\title{
Air-Breathing Bio-cathodes Based on Electro-Active Biochar from Pyrolysis of Giant Cane Stalks
}

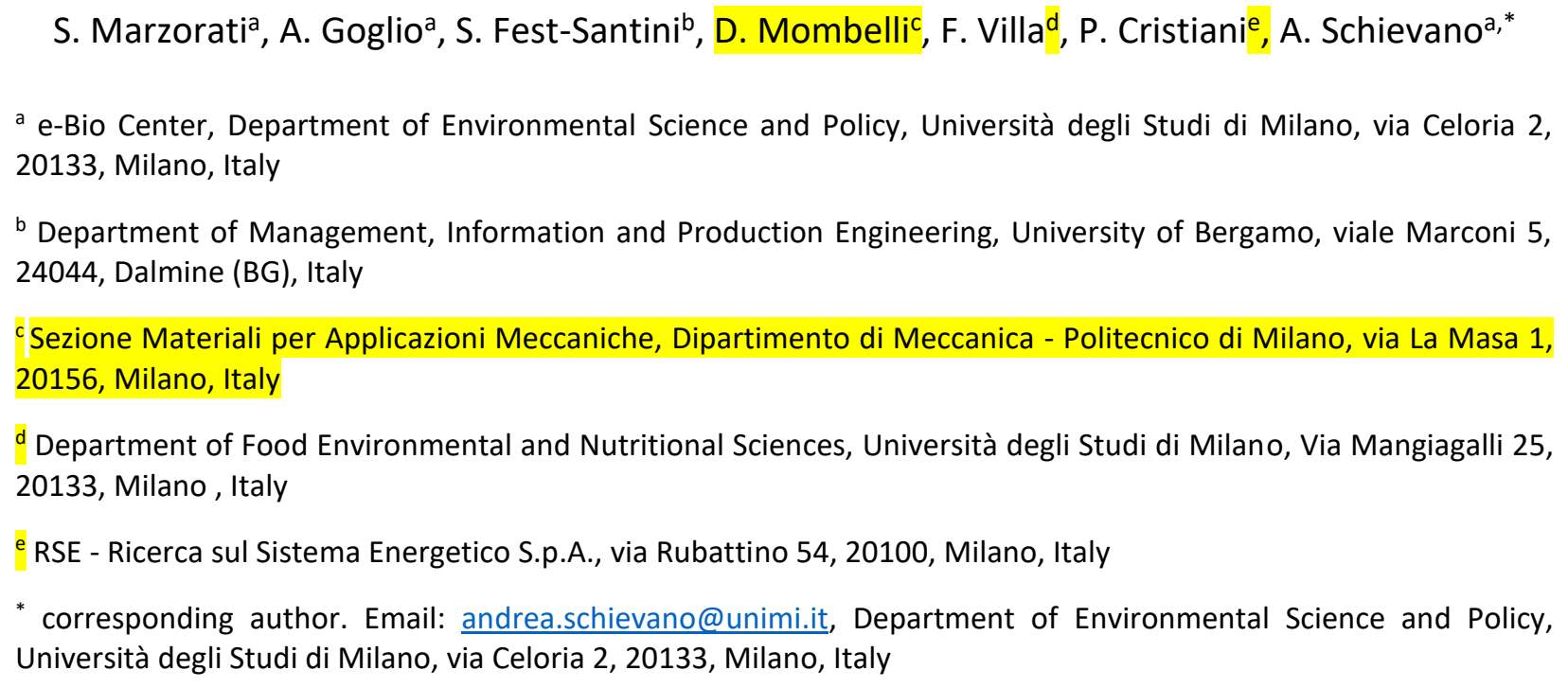

Keywords: Electroactive Biochar, e-biochar, Bio-electrochemical Systems, Air-cathode, Wastewater treatment, Pyrolysis

\section{ABSTRACT}

An innovative low-tech solution to fabricate electro-active biochar (e-biochar) electrodes for bioelectrochemical systems (BES) is proposed. Ligno-cellulosic stalks of Giant Cane (Arundo Donax L.) were subjected to pyrolysis treatment at $900{ }^{\circ} \mathrm{C}$ for $1 \mathrm{~h}$. The material kept its original hollow cylindrical shape, rigid morphology and porous texture, as confirmed by 3DX-ray micro-computed tomography. These characteristics are suitable for its use at the air-water interface in BES, as air-breathing bio-cathodes. BET (Brunauer-Emmett-Teller) specific surface area was equal to $114 \pm 4 \mathrm{~m}^{2} \mathrm{~g}^{-1}$, with more than $95 \%$ of pores in the microporosity range (pore diameter $<1 \mathrm{~nm}$ ). Surface electrocatalytic activity was sufficient to sustain oxygen reduction reaction at $\mathrm{pH} 7$, in terms of both onset potential $(-0.02 \mathrm{~V} \mathrm{vs} \mathrm{Ag} / \mathrm{AgCl})$ and reduction limiting current density $\left(1 \mathrm{~A} \mathrm{~m}^{-2}\right)$. Electrical resistivity measurements confirmed sufficient conductivity $\left(8.9 \times 10^{-3} \pm 1 \times 10^{-4} \Omega \mathrm{m}\right)$ of the material and Raman spectroscopy allowed to estimate a graphitization degree in relation to the $I_{D} / I_{G}$, equal to 2.26 . In parallel, the $e$-biochar were tested as airexposed bio-cathodes in BES, coupled to carbon cloth bio-anodes. After inoculation with wastewater from swine-farming, current densities were generated in the range of $100-150 \mathrm{~mA} \mathrm{~m}^{-2}$, along more than 2 
months of operation, under sodium acetate feeding. Confocal laser scanning imaging revealed consistent biofilm formation on the water-side surface of the cathodes, while a nearly-complete absence of it at the air-side.

These $e$-biochar electrodes might open innovative perspectives to scale-up BES for different applications. Here, consistent salts depositions on the material after 70 days of exposure to the wastewater, suggest that $e$-biochar biocathodes might serve to recycle nutrients to agricultural soils, through mineralsenriched biochar.

\section{INTRODUCTION}

Real scale application of bio-electrochemical systems (BES) has been facing the need to find an optimal balance between processes efficiencies and costs. Many researches are addressing to develop low-cost and environmentally-compatible materials to fabricate electrodes for large scale applications, such as wastewater treatment, soil bioremediation, etc. [1-3]. To date, the most competitive materials are based on carbon and include graphite-based rods, fiber brushes and granules, carbon-fiber cloths, carbon paper sheets, carbon felt and reticulated vitreous carbon $[1,2,4]$. They are selected due to their strong biocompatibility and inert properties at room temperature. The use of such materials as air-breathing cathodes has been coupled to the fabrication of microporous layers, made of activated carbon, pressed on carbon cloths (or other current collector) in the presence of polymeric binders (Nafion, PTFE, etc.) [5,6]. High surface area favors the cathodic oxygen reduction reaction (ORR) that needs the simultaneous presence of solid, liquid and gaseous phases. Microporous layers also act as gas diffusion layer at air-water interface, because the porous structure allows the diffusion of air in contact with the wet surface, impeding water to leak to the air-side [7-9]. Finally, high surface areas promote the formation of electroactive biofilms, able to highly boost a series of cascade reactions towards oxygen reduction which characterize the behavior of aerobic and anaerobic bio-cathode $[10,11]$. These 'structural' functions is really important for the application of such materials as air-exposed bio-cathodes [11].

However, these composites have some intrinsic limitations for large-scale applications of BES. A major challenge of commercial application of BES is often the high capital cost, especially material cost of anodes, cathodes, and separators. In a literature work [12], the capital cost of the BES was estimated to be around $100 \$ \mathrm{~m}^{-2}$ for carbon cloth anode and $5000 \$ \mathrm{~m}^{-3}$ for reactor. Some novel solutions with macroporous hollow fibers were recently proposed [13], still in the field of high-tech materials. After relatively short time of operation (typically after 1-3 months [14], or 1 year in some optimized case [15]), biofouling and salts deposition phenomena, tend to hinder cathode's performances. Unless restored by specific treatments $[16,17]$, such electrodes should be substituted by new ones. However, 
these materials are not fully recyclable. Carbon-cloths are based on mixtures of carbon fibers with nonbiogenic materials, such as polymeric binders (PTFE, Nafion, etc.). The compactness of the activated carbon mixtures on carbon-cloth electrodes is also guaranteed by the massive presence of water-resistant binders $[18,19]$.

In view of environmental large-scale applications of these electrodes, such as wastewater treatment or soil bioremediation, where harvesting electrical power is not the main goal [20,21], avoiding "high-tech", expensive and non-recyclable materials might result in a substantial advantage. An alternative approach should be based on a circular economy concept, where bio-electrodes are fabricated with bio-based and fully-recyclable materials. In this view, biomass-derived charcoal (biochar) represents a class of target materials that would satisfy this purpose. Biochar, the product of biomass thermochemical conversions, has been receiving increasing attention, for several applications. The versatility of biochar depends on its chemical and structural properties. Biochar is often porous and possesses high surface area [22]. Few groups recently started using biochar in BES [23-27], demonstrating its ability of promoting interspecies electron transfer [28]. For example, a variety of biomass-derived biochar (i.e. from pomelo peel and wood chips) was recently used in biofilm-driven water treatment processes possessing characteristics of low cost, high specific area, good biocompatibility and moderate electrical conductivity, which basically meet the requirements of biocathode materials $[29,30]$. In Table 1 some examples of biochar-based electrodes and their main properties is displayed.

82

\begin{tabular}{|c|c|c|c|c|c|}
\hline $\begin{array}{l}\text { Biomass } \\
\text { source }\end{array}$ & $\begin{array}{c}\text { Pyrolysis } \\
\text { temperature } \\
/{ }^{\circ} \mathrm{C}\end{array}$ & $\begin{array}{l}\text { SBET } \\
/ \mathbf{m}^{2} \mathbf{g}^{-1}\end{array}$ & Application & $\begin{array}{l}\text { Achieved power } \\
\text { density / } \mathbf{m W} \mathbf{~ m}^{-2}\end{array}$ & Reference \\
\hline $\begin{array}{l}\text { Pine wood } \\
\text { lumber }\end{array}$ & 1000 & 183.0 & $\begin{array}{l}\text { Electrocatalytic } \\
\text { support in } \\
\text { MFCs }\end{array}$ & 146.7 & [30] \\
\hline Pomelo peel & 1000 & 622.2 & $\begin{array}{c}\text { ORR } \\
\text { electrocatalysis }\end{array}$ & 799 & [29] \\
\hline $\begin{array}{l}\text { Pine sawdust } \\
\text { pellets }\end{array}$ & 1000 & 0.04 & $\begin{array}{c}\text { MFCs } \\
\text { electrodes }\end{array}$ & 457 & [25] \\
\hline Bananas & $550-900$ & $\begin{array}{l}105.2- \\
172.3\end{array}$ & MFCs cathode & 500 & [31] \\
\hline Chestnut shell & 900 & 468 & MFCs anodes & N/A & [32] \\
\hline
\end{tabular}

Table 1. Examples of biochars and their characteristics for microbial electrochemical application.

The fabrication of biochar as base for bio-electrodes, should aim at simultaneously enhancing electrical conductivity, abiotic electrocatalytic properties (e.g. ORR), biocompatibility and the capacity to host microbial biofilm communities. These properties would characterize a particular class of biochars. Here, we propose to call it 'electro-active biochar' or 'e-biochar'. The possibility to obtain $e$-biochar materials with intrinsic structural rigidity, would open the possibility to use them as air-breathing bio-cathodes at 
the air-water interface, in lieu of microporous layer/gas diffusion layer-based electrodes. Also, the availability of the original biomass in large amounts, at relatively low costs and environmental impacts, would also be a key-factor for success of $e$-biochar in large-scale BES. In a recent experiment, Giant Cane (Arundo donax L.) stalks were tested as air-water cylindrical separators, in air-cathode BES [33]. Giant Cane is a wild, perennial plant of emerging interest for sustainable biomass production [34]. In terms of cultivation inputs it is characterized by very low requirements; it easily adapts to a variety of soil and climatic conditions and has been recently considered one of the most promising biomass crops [35]. The plant's stalks, characterized by porous and rigid cylindrical structure, avoided water leaks to the air-side and allowed spontaneous electricity production using an organic-rich wastewater, with carbon-cloth electrodes [33]. Here, we fabricate air-breathing bio-cathodes with a rigid cylindrical shape, based on e-biochar obtained from controlled pyrolysis of Giant cane stalks. The physico-chemical and electrocatalytic properties were investigated, as well as their performance as air-breathing bio-cathodes in BES aimed at recovering nutrients from wastewater.

\section{MATERIALS AND METHODS}

\subsection{Fabrication of e-biochar air-cathodes}

Giant Canes were collected in Cascina Marianna (Landriano, PV) from the experimental fields of the Università degli Studi di Milano. Canes with an external homogeneous diameter of $2.5 \mathrm{~cm}$ and thickness of about $0.4 \mathrm{~cm}$ were selected, cleaned from leaves and cut into cylinders of $15 \mathrm{~cm}$ length. The canes were positioned in a quartz tube inside a horizontal furnace (Carbolite) and pyrolized according to the following protocol: $25 \mathrm{~min}$ at $25^{\circ} \mathrm{C}$, slow heating $\left(10^{\circ} \mathrm{C} \mathrm{min}-1\right)$ up to $900{ }^{\circ} \mathrm{C}, 1 \mathrm{~h}$ held at $900{ }^{\circ} \mathrm{C}$ and,

111 finally, cooling down to $25{ }^{\circ} \mathrm{C}$. Some literature methods were taken into account when choosing the 112 optimized temperature and temperature ramp in order to obtain a sufficiently graphitized sample [36113 38]. During all the pyrolysis treatment, nitrogen was flowing constantly at $14 \mathrm{NL} \mathrm{h}^{-1}$.

114 Hereafter, $900{ }^{\circ} \mathrm{C}$-pyrolized giant cane stalks will be named simply as 'e-biochar air-cathodes': $e$-BAC.

\subsection{Physical-chemical characterization}

116 The Brunauer-Emmett-Teller (BET) specific surface area (SSA) was obtained from $\mathrm{N}_{2}$ physisorption 117 isotherms at $77 \mathrm{~K}$ by an ASAP 2020 (Micrometitics) instrument. Before measurements, sample powders were outgassed at $110{ }^{\circ} \mathrm{C}$ for $3 \mathrm{~h}$ to remove adsorbed species. SSA value and porosity distribution were 
determined employing a multipoint BET interpolation of adsorption isotherms and BJH method, respectively.

Raman spectra were obtained on a Raman microscope (Micro-Raman Horiba Jobin Yvon HR800 UV) equipped with a CCD camera using $532 \mathrm{~nm}$ excitation laser. The acquired spectra were normalized to carry out the curve fitting of the G, D1, D2, D3 and D4 bands. The different bands were adjusted to Voigt type curves, finding the best fit to the experimental data without including the D2 band, as is usual with carbon black samples. The degree of graphitization has been expressed as the ratio of integral intensities of bands G and D1.

\subsection{Morphological characterization}

Scanning Electron Microscopy (SEM) was performed using a Zeiss SEM EVO 50 microscope.

Morphology description and porosity quantification were obtained from X-ray microcomputed tomography. The used microCT unit is based on an open type X-ray source 160 kVp @ $200 \mu \mathrm{A}$, a highprecision air-bearing rotating stage and Amorphous Silicon (a-Si) sensor array detector acquiring 16-bit grey level with a pixel matrix of $4096 \times 4096$ at 100 micrometers. Concerning further technical details of the microCT setup, refer to [39].

Fundamentals of tomography are based on the irradiation of a rotating specimen by an X-ray beam and recording the transmitted radiation for different angle steps allowing the 3D reconstruction. 2D grey-scale virtual slices are obtained through retro-projection. Different levels of grey correspond to certain attenuation coefficients, while every voxel represents an exact element of the digitalized object. Through segmentation and further image processing, information related to void space and solid can be extracted. The applicability of this characterization technique depends on the X-ray attenuation (absorption) of the material, which in turn depends on the atomic number of the chemical element, material density and object dimensions. e-BAC, like most of biological samples, is expected to be low density material making their 3D morphological inspection in the micrometer scale challenging. Here, this limitation are overcome working with low photon energy and a high dynamic range of the detector: 4000 projections with a resolution of $3.425 \mu \mathrm{m}$ (calibrated resolution, refer to [39]) acquired at $45 \mathrm{kV}, 30 \mu \mathrm{A}$ and $5300 \mathrm{~ms}$ integration time.

The global volumetric intensity histogram was expected to be bimodal with peaks referring to the void space and the material matrix. Instead, a further peak was observed having high intensity values whose indicate a high atomic number element. Thereby, a multi-level thresholding method, multi Otsu method, 
was utilized for the segmentation of the digitalized $e-B A C$ volume differencing in voids, $e-B A C$ matrix and high X-ray attenuation matter. The latter is a residue of pyrolysis and probably of mineral nature.

\subsection{Electrochemical characterizations}

Electrical resistivity measurements were performed setting the electrical contacts on opposite ends of the $e$-BACs. A potential scan was performed in the potential window $E=+0.1 /+0.5 \mathrm{~V}$ at a scan rate of 0.010 $V s^{-1}$. The electrical resistivity $\rho$ was calculated by the equation:

$$
\rho=R \frac{A}{l}
$$

Where $R$ is the resistance calculated by the slope of the $E$ vs I plot, $A$ is the area of the section of the $e$-BAC and $/$ is the length of the analyzed cylinder. Five different measurements of different sample lengths were performed to ensure the technique reproducibility.

Electrochemical active surface area (ECSA) determinations were performed by voltammetric curves recorded in $\mathrm{N}_{2}$-saturated $100 \mathrm{mM}$ PBS (Phosphate-buffered saline) solution in the double layer region at various scan rates as in previous work by Łukaszewski et al. [40]. A three-electrode configuration was used. A weighted piece of $e$-BAC was set as the working electrode, a Pt-wire was the counter electrode and an $\mathrm{Ag} / \mathrm{AgCl}$ (Amel) in $\mathrm{KCl}$ (sat.) was the reference electrode.

The specific mass capacitance $\left(C_{\mathrm{g}}\right)$ of the electrode was calculated from cyclic voltammograms according to the following equation:

$$
C_{g}=\frac{1}{m v\left(V_{c}-V_{a}\right)} \int_{V a}^{V c} i(V) d V
$$

where $C$ is the specific capacitance $\left(\mathrm{F} \mathrm{g}^{-1}\right), m$ is the mass $(\mathrm{g})$ of electroactive materials in the electrode, $v$ is the potential scan rate $\left(\mathrm{V} \mathrm{s}^{-1}\right), V_{c}$ and $V_{a}(\mathrm{~V})$ are the integration limits of the voltammetric curve, and $i(V)$ denotes the current density (A) [41].

ECSA $\left(\mathrm{m}^{2} \mathrm{~g}^{-1}\right)$ was then calculated by:

$$
E C S A=\frac{C_{g}}{C_{r e f}}
$$

and compared to the SSA as determined by BET measurements. The chosen reference value of capacity per the unit area [42] used in calculation was $C_{r e f}=9.57 \mu \mathrm{F} \mathrm{cm}^{-2}$.

\subsection{Oxygen reduction reaction (ORR) electrocatalytic activity}


Preliminary electrochemical characterization of the cathode was performed in $100 \mathrm{mM}$ PBS solution $(\mathrm{pH}$ 7.8) by cyclic voltammetry (CV), using a potentiostat (Materials $M$ 510). e-BACs were reduced into powders and dispersed in water $\left(10 \mathrm{mg} \mathrm{mL}^{-1}\right)$, sonicated for 5 min and $7 \mu \mathrm{L}$ were pipetted onto the glassy carbon tip (working electrode, geometric surface area: $\mathrm{A}=0.07 \mathrm{~cm}^{2}$ ) and dried in a bottom-up position. An electrochemical cell with a graphite counter electrode (Amel 201/S-016) and an Ag/AgCl reference electrode (Amel) in $\mathrm{KCl}$ (sat.) was used. Before $\mathrm{CV}$ recording, the working electrode was conditioned by cycling in $\mathrm{N}_{2}$ saturated solution within the $E=-1.000 /+0.250 \mathrm{~V}$ potential range. When using carbonate buffer solution, the potential range was $E=-1.2 /+0.1 \mathrm{~V}$. This step was followed by cycling in $\mathrm{O}_{2}$ saturated solution $\left(v=0.005 \mathrm{~V} \mathrm{~s}^{-1}\right)$.

\subsection{BES assembly and operation}

Fig. 1 shows a schematic of the BES experimental setup. The e-BACs (rigid carbonaceous cylinders) were sealed on the bottom side, by attaching a polymethyl methacrylate disk with an inert glue (Gomma Liquida, Bostik ${ }^{\circledast}$ ) and were ready to be used as hollow-cylindrical cathodes. The $e$-BACs were wrapped by synthetic felt (polyester fibers) as to avoid the short circuit with the anode. The anode was fixed around the external face of the cylinder, by a nylon wire, to completely wrap the cane outside the felt. This system was positioned in a plastic jar, immersed in the electrolyte. To prevent evaporation and oxygen diffusion in the wastewater, the jar was covered by a polystyrene disk, preserving anaerobic conditions, while letting air reach the internal cylindrical $e$-BACs. A plastic net guaranteed the anode's immersion in the electrolyte solution.

BES were run in triplicate in batch mode at $(25 \pm 1){ }^{\circ} \mathrm{C}$. The cell potential difference was recorded every 20 min across a proper external load using a multichannel Data Logger (Graphtec midi LOGGER GL820). The generated current $(I)$ was calculated by the Ohm's law $\left(I=V R^{-1}\right.$, where $R$ is the external resistive load and $V$ is the cell potential difference) and normalized by the cathode's area to obtain the current density (j).
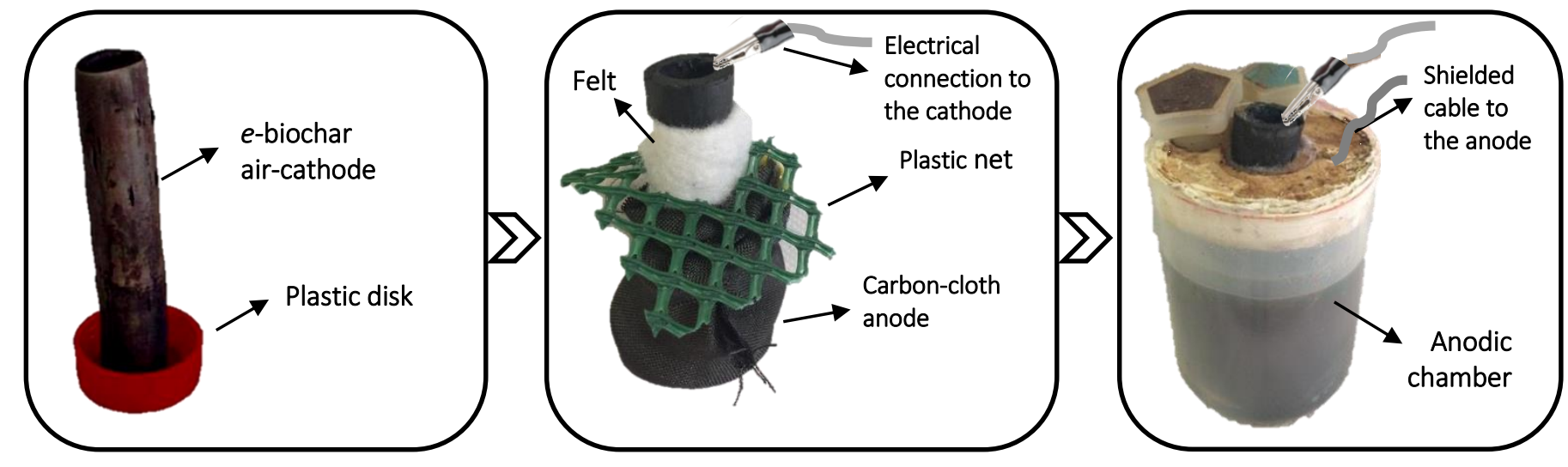
Fig. 1. Schematic of the BES experimental setup.

206

207

208

209

210

211

212

213

214

215

216

217

218

219

220

221

222

Anodes were made of plain carbon-cloth (SAATI C1), without any surface treatment. $28 \times 9 \mathrm{~cm}$ carboncloth rectangles were cut and electrically connected to a plastic-insulated copper wire. The electrical connection was then protected by two layers of a bi-component epoxy resin (PROCHIMA COLLA EPOXY).

The inoculum was a swine manure collected in a pig-farm near Milan (Italy). Concentrated swine manure $\left(120 \mathrm{~mL}, \mathrm{COD}=6 \mathrm{~g} \mathrm{~L}^{-1}\right)$ were added to the anodic chamber at the beginning of the experiment $(\mathrm{t}=0)$. Distilled water $(0.5 \mathrm{~mL})$ was dropped into the cathodic chamber ensure the cathode's complete wetness and electrolytic contact.

After the first decline of the current generated by the system, the anolyte was removed and then refilled by the same amount $(120 \mathrm{~mL})$, this time composed half by the same swine manure and half by a synthetic medium. The synthetic medium was chosen according to literature $[43,44]$. Briefly, it was a $100 \mathrm{mM}$ phosphate buffer solution (PBS; $70 \mathrm{~g} \mathrm{Na} 2 \mathrm{HPO}_{4}$ and $12 \mathrm{~g} \mathrm{KH}_{2} \mathrm{PO}_{4}$ per liter) with the following components in $1 \mathrm{~L}$ of deionized water: $\mathrm{NH}_{4} \mathrm{Cl}(0.41 \mathrm{~g}) ; 1 \mathrm{~mL}$ of $4 \mathrm{~g} \mathrm{~L}^{-1} \mathrm{FeCl}_{2}$ solution; $10 \mathrm{~mL}$ of mineral medium. The mineral media had the composition described by Parameswaran et al. [44]: EDTA (0.5 g L$\left.{ }^{-1}\right) ; \mathrm{CoCl}_{2} \bullet 6 \mathrm{H}_{2} \mathrm{O}$ $\left(0.082 \mathrm{~g} \mathrm{~L}^{-1}\right) ; \mathrm{CaCl}_{2} \bullet 2 \mathrm{H}_{2} \mathrm{O}\left(0.114 \mathrm{~g} \mathrm{~L}^{-1}\right) ; \mathrm{H}_{3} \mathrm{BO}_{3}\left(0.01 \mathrm{~g} \mathrm{~L}^{-1}\right) ; \mathrm{Na}_{2} \mathrm{MoO}_{4} \bullet 2 \mathrm{H}_{2} \mathrm{O}\left(0.02 \mathrm{~g} \mathrm{~L}^{-1}\right) ; \mathrm{Na}_{2} \mathrm{SeO}_{3}\left(0.001 \mathrm{~g} \mathrm{~L}^{-}\right.$ $\left.{ }^{1}\right) ; \mathrm{Na}_{2} \mathrm{WO}_{4} \bullet 2 \mathrm{H}_{2} \mathrm{O}\left(0.01 \mathrm{~g} \mathrm{~L}^{-1}\right) ; \mathrm{NiCl}_{2} \bullet 6 \mathrm{H}_{2} \mathrm{O}\left(0.02 \mathrm{~g} \mathrm{~L}^{-1}\right) ; \mathrm{MgCl}_{2}\left(1.16 \mathrm{~g} \mathrm{~L}^{-1}\right) ; \mathrm{MnCl}_{2} \bullet 4 \mathrm{H}_{2} \mathrm{O}\left(0.59 \mathrm{~g} \mathrm{~L}^{-1}\right) ; \mathrm{ZnCl}_{2}(0.05$ $\left.\mathrm{g} \mathrm{L}^{-1}\right) ; \mathrm{CuSO}_{4} \bullet 5 \mathrm{H}_{2} \mathrm{O}\left(0.01 \mathrm{~g} \mathrm{~L}^{-1}\right) ; \operatorname{AIK}\left(\mathrm{SO}_{4}\right)_{2}\left(0.01 \mathrm{~g} \mathrm{~L}^{-1}\right)$.

After the subsequent current decline, the anolyte was removed and refilled by the same amount of electrolyte $(120 \mathrm{~mL})$, this time composed entirely by the synthetic medium added with $7.7 \mathrm{~g} \mathrm{~L}^{-1}$ of sodium acetate. This refill established the end of the acclimation phase and the starting point of the operational period of each system. A schematic overview of the acclimation and operational phases electrolytes is given in Table 2.

\begin{tabular}{|c|c|c|c|c|c|}
\hline \multicolumn{2}{|c|}{ ACCLIMATION } & \multicolumn{4}{c|}{ OPERATIONAL PERIOD } \\
\hline A1: & A2: & P1: & P2: & P3: & P4: \\
Day 0-Day 17 & Day 17- Day 25 & Day 25-Day 40 & Day 40-Day 58 & Day 58-Day 72 & Day 72-Day 90 \\
\hline & $60 \mathrm{~mL}$ swine & $7.7 \mathrm{~g} \mathrm{~L}^{-1}$ & $7.7 \mathrm{~g} \mathrm{~L}^{-1}$ & $7.7 \mathrm{~g} \mathrm{~L}^{-1}$ & $7.7 \mathrm{~g} \mathrm{~L}^{-1}$ \\
& manure & $\mathrm{CH}_{3} \mathrm{COONa}$ in & $\mathrm{CH}_{3} \mathrm{COONa}$ in & $\mathrm{CH}_{3} \mathrm{COONa}$ in & $\mathrm{CH}_{3} \mathrm{COONa}$ in \\
$120 \mathrm{~mL}$ swine & + & $120 \mathrm{~mL}$ & $120 \mathrm{~mL}$ & $120 \mathrm{~mL}$ & $120 \mathrm{~mL}$ \\
manure & $60 \mathrm{~mL}$ synthetic & synthethic & synthethic & synthethic & synthethic \\
& medium & medium & medium & medium & medium \\
\hline
\end{tabular}

Table 2. Timeline and details of each experimental phase. 
Along the experiment, power curves were periodically recorded with a two-electrode configuration. Before each electrochemical measurement, $1 \mathrm{~h}$ equilibration time was found necessary to allow the BES system, disconnected from the data logger, to reach its open circuit potential (OCP). The anode was set as working electrode and the cathode as reference electrode. A linear sweep polarization $\left(v=0.010 \mathrm{~V} \mathrm{\textrm {min } ^ { - }}\right.$

$232{ }^{1}$ ) was recorded from the cell OCP to $10 \mathrm{mV}$. Power $(P)$ was calculated by $P=I V$ and plotted vs current 233 density (j).

\subsection{Biofilms visualization by fluorescence microscopy}

235 Biofilms growing on both external and internal sides of $e$-BAC bio-cathodes were visualized by 236 fluorescence microscopy. The samples were collected using adhesive tape strips that reproduce the mirror 237 image of the biofilm present in the selected area. The lectin Concanavalin A-Texas Red conjugate (ConA, 238 Invitrogen, Italy) was used to visualize the polysaccharide component of biofilm matrix (extracellular 239 polymeric substances, EPS), whereas the fluorescent nucleic acid stain 4', 6-diamidino-2-phenylindole 240 (DAPI, Sigma-Aldrich srl, Milan, Italy) was used to display biofilm cells. Samples were incubated with 200 $241 \mu \mathrm{g} \mathrm{LL}^{-1}$ ConA and $10 \mu \mathrm{g} \mathrm{mL}^{-1}$ DAPI solution in $\mathrm{ddH}_{2} \mathrm{O}$ at room temperature in the dark for 30 min, and then 242 rinsed. Images were collected using a Leica DM 4000 B microscope equipped with specific filter sets, and 243 a 63X 0.7NA water immersion objective. Digital images acquired using the CoolSNAP CF digital camera 244 (Photometrics Roper Scientific) and elaborated using the ImageJ 1.34s software.

\subsection{ICP-MS}

246

Inductively coupled plasma mass spectrometry (ICP-MS) was used to measure total contents of single elements in the $e$-BAC at $\mathrm{t}=0$ and $\mathrm{t}=70$ days. Weighted amounts of materials were mineralized by a microwave digestor system (Anton Paar MULTIWAVE-ECO) in Teflon tubes filled with $10 \mathrm{~mL}$ of $65 \% \mathrm{HNO}_{3}$ by applying a one-step temperature ramp $\left(210^{\circ} \mathrm{C}\right.$ reached in $10 \mathrm{~min}$ and maintained for further $\left.10 \mathrm{~min}\right)$. After 20 min of cooling time, the mineralized samples were transferred in polypropylene test tubes. Solutions of mineralized samples were diluted 1:100 with $0.3 \mathrm{M} \mathrm{HNO}_{3}$ in MILLI-Q water and the concentration of elements was measured by ICP-MS (BRUKER Aurora-M90 ICP-MS). An aliquot of a $2 \mathrm{mg}$ $\mathrm{L}^{-1}$ of an internal standard solution (72Ge, 89Y, 159Tb) was added both to samples and calibration curve using CRI (Collision-Reaction-Interface) with an $\mathrm{H}_{2}$ flow of $75 \mathrm{~mL} \mathrm{~min}^{-1}$ flown through skimmer cone. 


\subsection{Rigid and porous cylindrical structure}

After the $900{ }^{\circ} \mathrm{C}$-pyrolysis treatment, the materials maintained its structural rigidity and cylindrical shape (Fig. 1). This was the first fundamental requirement fulfilled by this experiment. By sealing its bottom and immersing its external surface in water, the internal surface got wet because of water penetration but without filling the internal part of the cylinder over time. This means that the porous structure of the material was enough to let water pass through it. At the same time, pores volume and diameters were impeding fast flow of the liquid towards the air-exposed side. At the air-water interface, evaporation has time to take place, being evaporation and water flow well balanced. Similar approaches in BES field were developed by other research groups, introducing air-water separators (such as terracotta ref [45]) which had the function of hindering water to flow out rapidly and without introducing too high resistance. The 'terracotta' (typical porosity 60-500 nm $[3,46]$ ) gets imbibed and acts as porous medium that allows electrolytes mobility. In a previous experiment from our group [33], we employed a ligno-cellulosic biomass (Giant Cane), as separator between electrodes. However, since plant materials underwent partial biodegradation over time, they released elements inside the anolytes. In each of these examples however, the separator was acting as the structural element of the BES. In this experiment we verified that, by direct pyrolysis of the biomass, the cathodic electrode itself is able to give the structure to the BES, without any further separator (and hence resistance) addition.

A)

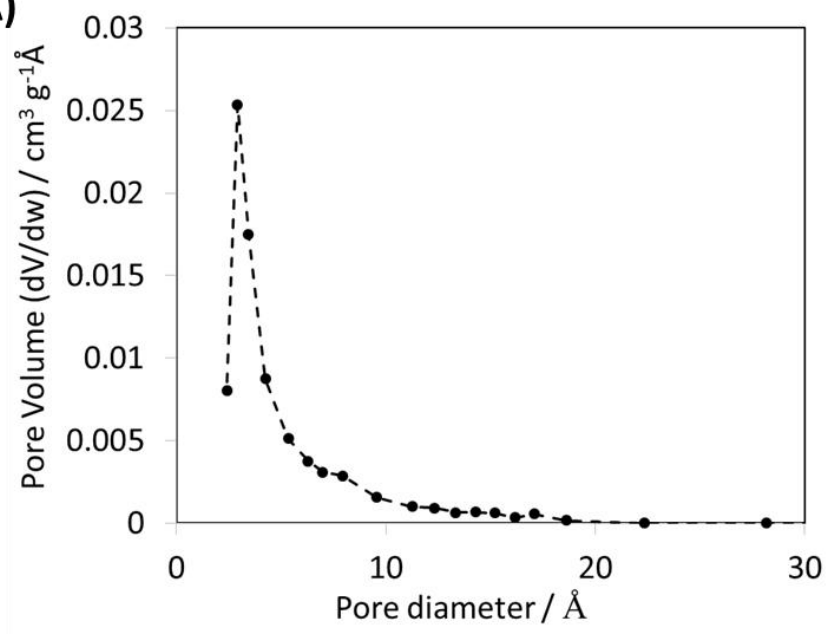

B)

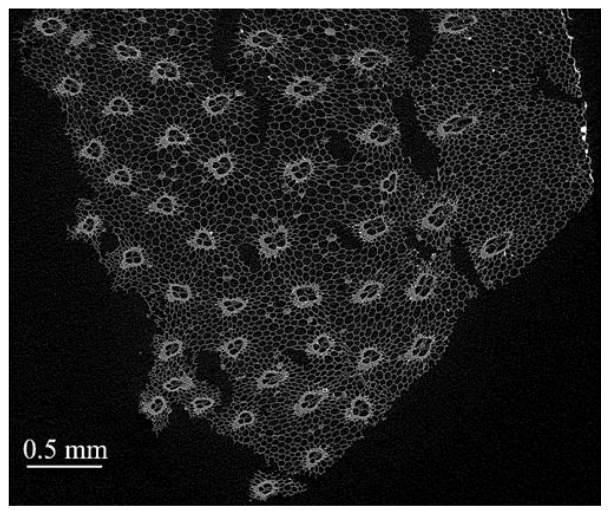

Fig. 2 A) Pore size distribution by BJH analysis. B) MicroCT cross-sections of e-biochar air-cathode.

$e$-BACs underwent $\mathrm{N}_{2}$ adsorption/desorption, to measure the BET specific surface area (SSA) which was found equal to $114 \pm 4 \mathrm{~m}^{2} \mathrm{~g}^{-1}$. Higher specific surface area was hence obtained, with respect to the dry and non-pyrolysed Giant Cane, as reported in the literature by Basso et al. $\left(0.7 \mathrm{~m}^{2} \mathrm{~g}^{-1}\right)$ [36]. The same 
authors also reported the specific surface area value obtained treating Giant Cane stems at $800{ }^{\circ} \mathrm{C}$, a 280 temperature similar to what was used in the present work and they obtained $101 \mathrm{~m}^{2} \mathrm{~g}^{-1}$ [36]. This is in line with the specific surface area measured for e-BACs. From the analysis of the porosity, the great part (> 95\%) of e-BAC surface area is comprised in pores with a diameter smaller than $1 \mathrm{~nm}$. Basso et al. [36] found similar results for the $800{ }^{\circ} \mathrm{C}$ treated sample, with a mean pore radius of about $1.1 \mathrm{~nm}$. Microporosity is therefore the predominant range of pores in the analysed sample, as displayed in Fig. 2A, showing the pore size distribution.

The largest pores, in the macroporosity range, are not quantifiable by BJH analysis and a 3D microcomputed tomography was performed in order to evaluate the morphology of the pyrolized sample in the $\mu \mathrm{m}$ range. A sub-volume of $51.44 \mathrm{~mm}^{3}$ were analyzed containing $74.77 \%$ voids, $25.17 \%$ e-BAC matrix and $0.06 \%$ residue of pyrolysis (volume \%). In Fig. 2B, a microCT cross section of e-BAC is shown. The structure of the vascular bundles is still present after the pyrolysis. From the inner to the outer surface, a continuous accumulation of vascular bundles can be observed resisting greater static stresses in this zone. The bundle fiber thickness is in the range of 15 and $25 \mu \mathrm{m}$. These points were confirmed by Rüggeberg et al. [47], describing the morphological and anatomical features at different structural levels of Giant Cane. The culms are subdivided into nodes and internodes with numerous isolated vascular bundles with enclosing fibre rings embedded in lignified parenchyma further stiffen the culm, as shown in Fig. 2B after the pyrolysis process. The same features were found in the cross section images in the paper by Rüggeberg et al. [47].

Analyzing the inner surface and volume of the void space, the specific surface area was determined equal to $29 \mathrm{~mm}^{2} / \mathrm{mm}^{3}$. From the arithmetic mean value of the volume-related surface area of single pores approximated as long cylinders, the equivalent diameter is estimated to be about $38.9 \mu \mathrm{m}$. Further, the average particle diameter of pyrolysis residue is to be about $21.9 \mu \mathrm{m}$.

\subsection{Graphitization degree and electrical conductivity}

Another important parameter to be determined for e-BACs is its electrical conductivity. Raman spectroscopy is one of the most useful tools to establish the graphitization degree, which correlates with the electrical resistance (and hence the electrical conductivity) [48]. Fig. 3A shows Raman spectra of $e$ BACs which displays the two typical carbon bands: the $D$ band between 1300 and $1400 \mathrm{~cm}^{-1}$, related to vibrations that are forbidden in perfect graphite and become active in the presence of disorder and defects, and the $\mathrm{G}$ band between 1500 and $1600 \mathrm{~cm}^{-1}$ attributable to in-plane bond-stretching vibrations of trigonally bonded carbon atoms ( $\mathrm{sp}^{2}$ centers)[49]. From the ratio between the $\mathrm{D}$ and $\mathrm{G}$ peaks intensity, 
310 it is possible to discern the presence of disordered/ordered graphene structures affecting the sample

311 conductivity. Usually, upon annealing, the $D$ peak becomes more intense respect to the $G$ one [48]. An

312 increase in the number and size of graphitic clusters is known to translate into an increase in $I_{D} / I_{G}$ in 313 amorphous carbons, according to the three-stage model of Ferrari et al. [48]. A $I_{D} / I_{G}$, equal to 2.26 was

314 indeed found for the e-BAC. This is also coherent with other measurements found in the literature [50].

315 Starting from the acquired spectrum and using the equation provided by Cancado et al. [51], $8.46 \mathrm{~nm}$ was 316 determined as the crystallite size.

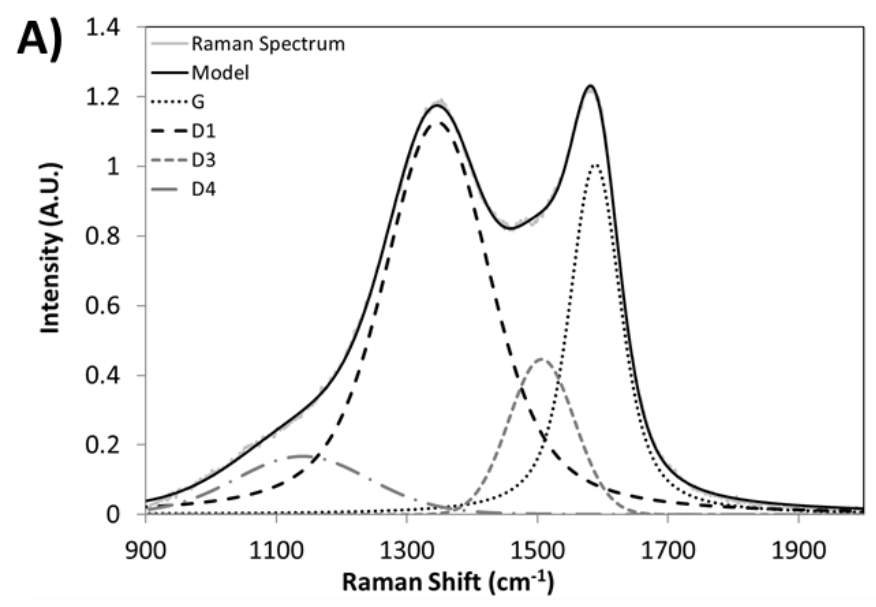

B)

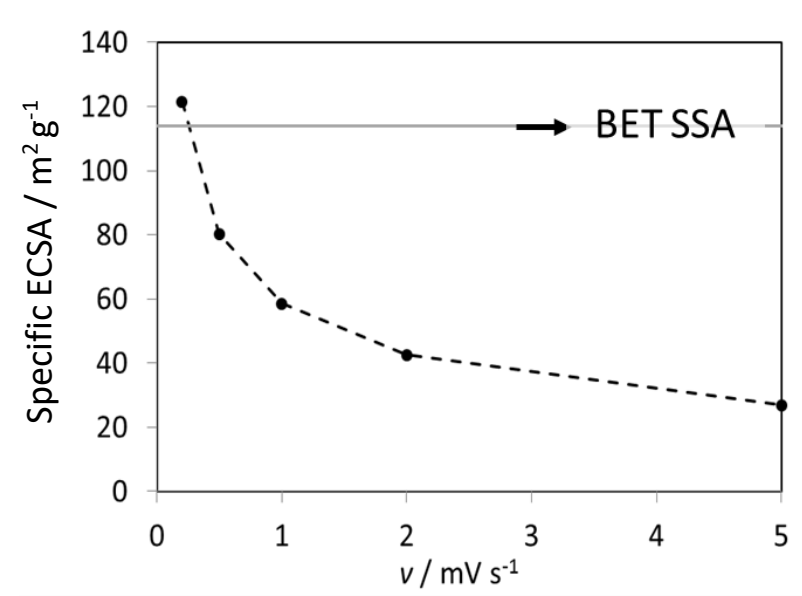

C)

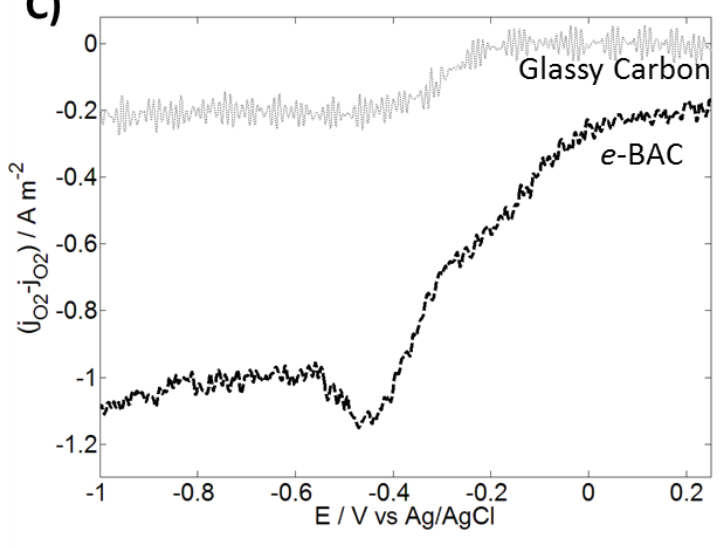

318

319

320

321

322

323

324

Fig. 3 A) Raman spectrum of $e$-biochar air-cathodes. B) specific ECSA determinations. C) ORR cathodic polarization curves.

The electrical c of $e$-BACs was measured and compared to other carbon materials in the literature. The method applied in this work on e-BACs, resulted in an electrical resistivity value of $8.9 \times 10^{-3} \pm 1 \times 10^{-4} \Omega \mathrm{m}$. As expected, this value indicates a higher resistivity with respect to graphite. Graphite is well-known to possess electrical resistivity varying depending on the measurement axes $[52,53]$ and equal to $2.50 \times 10^{-6}$ 
- $5.00 \times 10^{-6} \Omega \mathrm{m}$ if measured parallel to the basal plane and about $3.00 \times 10^{-3} \Omega \mathrm{m}$ if measured perpendicularly to the basal plane [53]. However, the e-BACs matrix displays a comparable or lower resistivity, and hence a higher conductivity, as compared to other biochar-based materials, reported in the literature. For instance, resistivity was around $5.15 \times 10^{-3} \Omega \mathrm{m}$ for activated carbon [54], $0.98 \Omega \mathrm{m}$ for rice straw treated at $800{ }^{\circ} \mathrm{C}[55]$.

Double layer charging currents were then recorded within the scan rates range between $0.2 \mathrm{mV} \mathrm{s}^{-1}$ and 5 $\mathrm{mV} \mathrm{s}^{-1}$. Higher scan rates avoided the system to reach an electrical charging equilibrium due to the large presence of micropores, hindering ions diffusion inside pores. Fig. 3B shows the values of specific ECSA, calculated at different scan rates. As expected, the real available surface area decreased with increasing scan rates. This is due to the presence of micropores, hindering ions diffusion inside the material, hence unable to reach an electrical charging equilibrium if the potential variation over time is too fast.

The highest value of specific ECSA was obtained by the lowest scan rate $\left(0.2 \mathrm{mV} \mathrm{s}^{-1}\right)$ and this value is in fact very similar to the BET specific surface area $\left(114 \pm 4 \mathrm{~m}^{2} \mathrm{~g}^{-1}\right)$. This means that the electric surface area corresponds to the BET surface area only with scan rates equal or lower than $0.2 \mathrm{mV} \mathrm{s}^{-1}$.

In general, characterization of carbon/solution interfaces is more complex than that of metals [56]. As explained by equation (2), the weak point of the calculation is relative to the choice of the appropriate $C_{\text {ref }}$ value. An improper choice of $C_{\text {ref }}$ might drive to unreliable calculations of real electrical SSA. Pore accessibility is the most critical point dealing with capacitance of carbon materials [56]. Other problems arise due to the fact that carbons are not ideally polarizable, as noble metals (e.g. $\mathrm{Hg}$ ) are. This is attributable to surface oxidation or intercalation processes [56].

Here, the chosen reference value of specific capacity was $C_{\text {ref }}=9.57 \mu \mathrm{F} \mathrm{cm}{ }^{-2}$, for similarity to materials with similar characteristics [42]. This value refers to Vulcan XC72, a material with similar BET surface area $\left(131.6 \mathrm{~m}^{2} \mathrm{~g}^{-1}\right)$, as compared to $e$-BACs $\left(114 \pm 4 \mathrm{~m}^{2} \mathrm{~g}^{-1}\right)$. Also, the specific mass capacitance of this reference material $\left(12.6 \mu \mathrm{F} \mathrm{g}^{-1}\right)$ is very close to that one calculated for e-BACs sample at the lowest scan rate (11.6 $\mu \mathrm{F}$ $\left.\mathrm{g}^{-1}\right)$.

\subsection{ORR electrocatalytic activity}

The electrocatalytic properties of e-BAC towards the ORR were investigated. Fig. $3 \mathrm{C}$ shows the ORR polarization curves for a glassy carbon electrode (GC) covered by the $e$-BAC powder. For comparison, the figure also reports a second polarization curve for the bare GC electrode, recorded in the same conditions. Cathodic limiting current densities (normalized by the geometric area of the GC electrode) were equal to $-1 \mathrm{~A} \mathrm{~m}^{-2}$ and $-0.2 \mathrm{~A} \mathrm{~m}^{-2}$ for $e$-BAC and GC, respectively. The presence of the e-BAC catalyst not only 
enhanced the limiting currents, but also shifted the onset potential from $-0.200 \mathrm{~V} v \mathrm{Ag} / \mathrm{AgCl}\left(\mathrm{E}_{1 / 2}=-0.3 \mathrm{~V}\right.$ vs $\mathrm{Ag} / \mathrm{AgCl})$ to cathodic value of $-0.020 \mathrm{~V}$ vs $\mathrm{Ag} / \mathrm{AgCl}\left(\mathrm{E}_{1 / 2}=-0.2 \mathrm{~V}\right.$ vs $\left.\mathrm{Ag} / \mathrm{AgCl}\right)$.

As compared to other catalysts used in the literature to maximize current generation in fuel cells or microbial fuel cells, e-BAC produced relatively low ORR currents displaying higher overpotentials. For example, Liu et al. doped graphene-based cathodes with nitrogen heteroatoms [57]: the onset potential was found to be $200 \mathrm{mV}$ less cathodic, compared to $e-\mathrm{BAC}$, at the same $\mathrm{pH}$ conditions. Also, reduction currents were higher by one order of magnitude. Many other examples in the literature were presented in the direction of electrocatalytic activity enhancement without any precious metal content [58]. The kinetics characteristics of these kind of carbon towards ORR are better [58] compared to what obtained in this work, nevertheless, the production of these carbon-based catalysts is usually time-consuming. Moreover, synthetic or costly reactants are employed. Instead, in this work, despite lower electrocatalytic performance were achieved, e-BACs were fabricated with facile pyrolysis of Giant Cane stalks, without any kind of pre- or post-treatment. This aspect is advantageous in terms of simplicity in electrodes preparation and a potential greater suitability for applications in natural environments, for processes such as biodegradation of pollutants, where even a slow electrocatalysis could be enough.

\section{4 e-biochar air-exposed bio-cathodes performances in BES}

$372 e$-BACs were tested as potential hosts of electroactive biofilm communities, as air-exposed bio-cathodes.

373 After assembling e-BACs in simple BES architectures as shown in Fig. 1, currents were monitored over 374 time. The current density trends, reported in Fig. 4A, showed a standard deviation between the triplicates of about $5 \%$. During a first acclimation period (A1), the anolyte was totally composed by swine manure as inoculum. After an initial and expected delay, around day 12 the systems started producing current, up to a maximum of about $100 \mathrm{~mA} \mathrm{~m}^{-2}$. In a second acclimation period (A2), during which half of the anolyte was substituted by the synthetic medium, the systems produced less current compared to the previous cycle (with a maximum of about $70 \mathrm{~mA} \mathrm{~m}^{-2}$ ), and this might be due to the sudden replacement of the medium of the bacteria colonizing the electrodes which still needed to adapt to the new environment. After the A2 phase, the real operational period (P1) began, characterized by the whole presence of the synthetic medium as the anolyte and sodium acetate $\left(7.7 \mathrm{~g} \mathrm{~L}^{-1}\right)$ as the standard feed for bacteria. During cycle P1 the current production was comparable to the last cycle of acclimation. This, once again, could be related to the last sudden replacement of the bacteria environment. In a second acetate batch cycle (P2) in fact the recorded current densities are higher and equal to about $130 \mathrm{~mA} \mathrm{~m}^{-2}$. However, during the 
maximum current densities of $25 \mathrm{~mA} \mathrm{~m}^{-2}$ and $15 \mathrm{~mA} \mathrm{~m}^{-2}$ in cycles $\mathrm{P} 3$ and $\mathrm{P} 4$, respectively. Also power densities were much lower (less than $5 \mathrm{~mW} \mathrm{~m}^{-2}$ ) as compared to the starting operational period of the system, as reported in Fig. 4B.
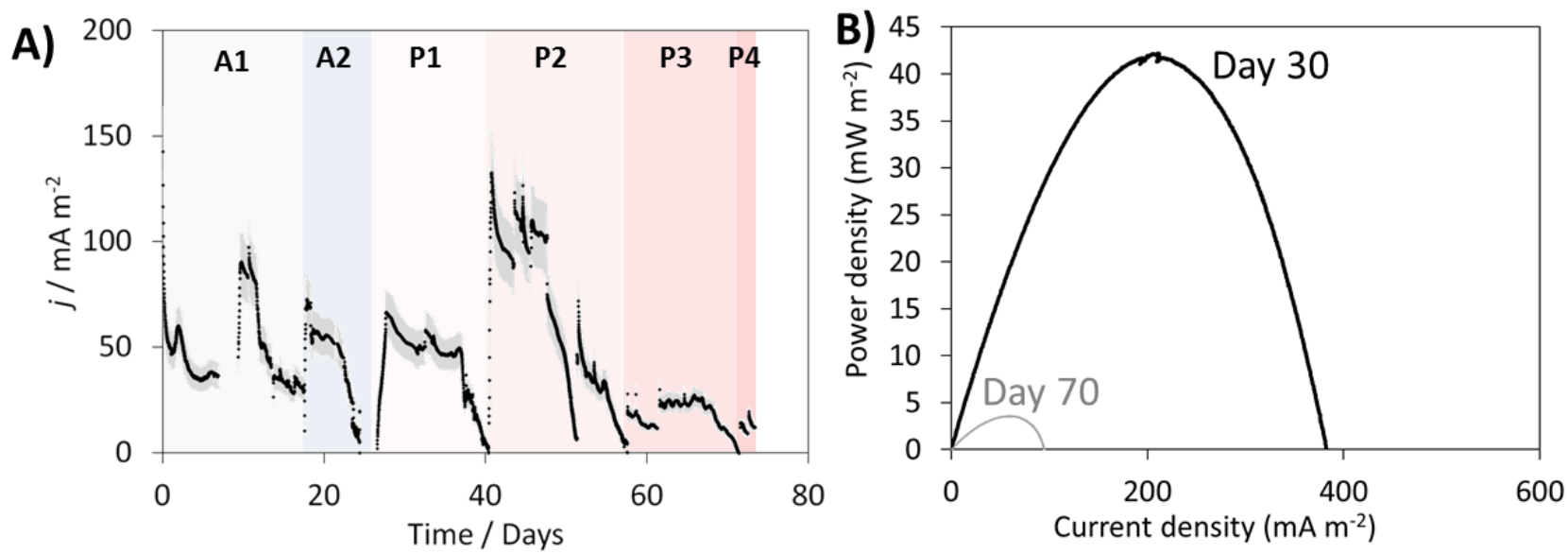

Fig. 4. A) Trends of current density obtained by BES, equipped with e-biochar air-cathode. Black line shows the average trend, the grey region shows the standard deviation of triplicate experiments. In acclimation batch-cycles (A1, A2) swine manure was fed to the anodic chamber; in successive batch cycles (P1-P4) sodium acetate $\left(7.7 \mathrm{~g} \mathrm{~L}^{-1}\right)$ was used as carbon source. B) Power density curves at day 30 and at day 70 .

Representative biofilm structures observed for the e-BAC bio-cathode are presented in Fig. 5 . The images display microbial colonization of the water-side of the cathode (Fig. 5 A-B), exposed to bacteria. The biofilm is characterized by a marked structural heterogeneity, showing several morphotypes of microorganisms assembled in dense clusters. The lectin-binding analysis combined with fluorescence microscopy revealed the presence of extracellular polymeric substances glycol-conjugates (i.e. polysaccharides, including those ones covalently linked to proteins and/or lipids) in all the samples colonizing the external side of an e-BAC.

By contrast, the inner surface of an e-BAC, exposed to air was poorly colonized, showing few coccoid morphotypes organized in small assemblages. No signal derived from the lectin-binding analysis was detected, indicating the absence of an extracellular matrix typical of mature and well structured biofilms (Fig. 5C). 

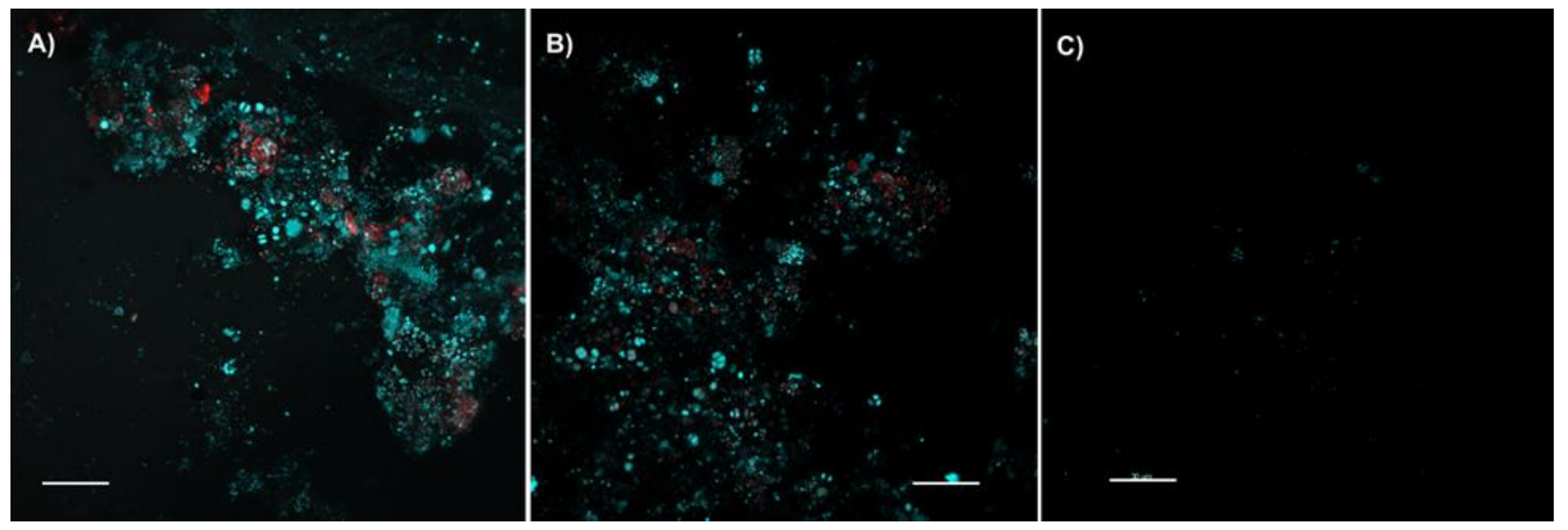

413 Fig. 5. Fluorescent images of the biofilms colonizing the water-side (panel A-B) and air-side (panel C) of a e-biochar air-exposed bio-cathode. Color key: Biofilm cells, blue (DAPI); EPS matrix, red (ConA). Scale bars $30 \mu \mathrm{m}$.

These results indicate that the dimension of pores of the e-biochar impeded the passage of microorganisms from the anolyte towards the air-side. In this region, the electroactive sites of $e$-BAC exposed to air catalyse the ORR with an electroactivity that was previously investigated by electrochemical reduction polarization curves measured on e-BAC powder (Fig. 3B). However, it cannot be excluded that

420 bacteria, colonizing the water-side of the cathode facing the anolyte, take part in the cathodic oxygen 421 reduction reaction, being in contact with a region where oxygen is likely present, even if at low 422 concentration. e-BAC cylinder could be in fact able to diffuse $\mathrm{O}_{2}$ throughout its thickness, until it reaches 423 the microorganisms. Furthermore, the reduced products from the metabolism of bacteria, such as 424 sulphides, could be able to sustain a chain of cathodic reactions diffusing through the cathode porosity. 425 These aspects that characterized the electrochemical behavior of air-breathing carbon bio-cathode, as 426 discussed in previous works [10,46,59], deserve further investigations and detailed studies.

\subsection{Possible applications of e-biochar air-exposed bio-cathodes}

428 Power density curves (Fig. 4B) report maximum of about $40 \mathrm{~mW} \mathrm{~m}^{-2}$, recorded at day 30 , during the 429 plateau reached under feeding condition. Similar values were obtained in low-tech BES, e.g. with Giant 430 Cane stalk or terracotta are employed as air-water separators, using carbon cloth-based electrodes $431[33,46]$. In general, higher-tech microbial fuel cells aimed at energy harvesting in the literature achieve 432 higher current and power densities, as compared to the $e$-BAC $[60,61]$. Further work would be needed to 433 optimize abiotic ORR reactions, in the direction of introducing more active electrocatalytic centers and 434 increase the ECSA and [62], in parallel, promote microbial colonization of e-BAC [63]. 
However, energy harvesting and maximizing power densities might not be the main goal in many

436 applications of e-BACs. For example, terracotta-based microbial fuel cells systems were utilized by Gajda

437 et al. as self- powered wastewater electrolyser for electrocoagulation of heavy metals, caustic production

438 at cathode $(\mathrm{pH}>10)$ and $\mathrm{CO}_{2}$ sequestration [64]. They also observed how current generation in cylindrical

439 terracotta microbial fuel cells contributed to generate an electro-osmotic drag and reported catholyte

440 formation (attributed to water transport ) in proportion to power performance [65]. $\mathrm{pH}$ increase was

441 demonstrated to be responsible of inorganic salts deposition (e.g carbonates precipitation) [66] and

442 accumulation as a layer between the cathode and the biofilm, thus preventing charge transfer processes.

443 Here, the relatively low power density (Fig. 4B) was sufficient to generate an electrical field, driving ions

444 migration at cathode and inducing salts deposition phenomena (likely thanks also to locally increased $\mathrm{pH}$

445 conditions [67]). The observed decrease in currents and maximum power density (Fig. 4) fit with the

446 hypothesis of salts deposition phenomena. After 70 operational days, $e$-BAC appeared covered by salts

447 deposits (Fig. 6). The materials were analyzed by SEM microscopy, ICP-MS and BET, to detect the presence

448 and the amount of elements that underwent deposition over time. In SEM images (Fig. 6A), the structure

449 of the pristine, pyrolysed Giant Cane is clearly visible. In Fig 6B, the presence of crystals of different shapes,

450 deposited on the external side of the e-BAC cylinder, facing the wastewater is massive. 

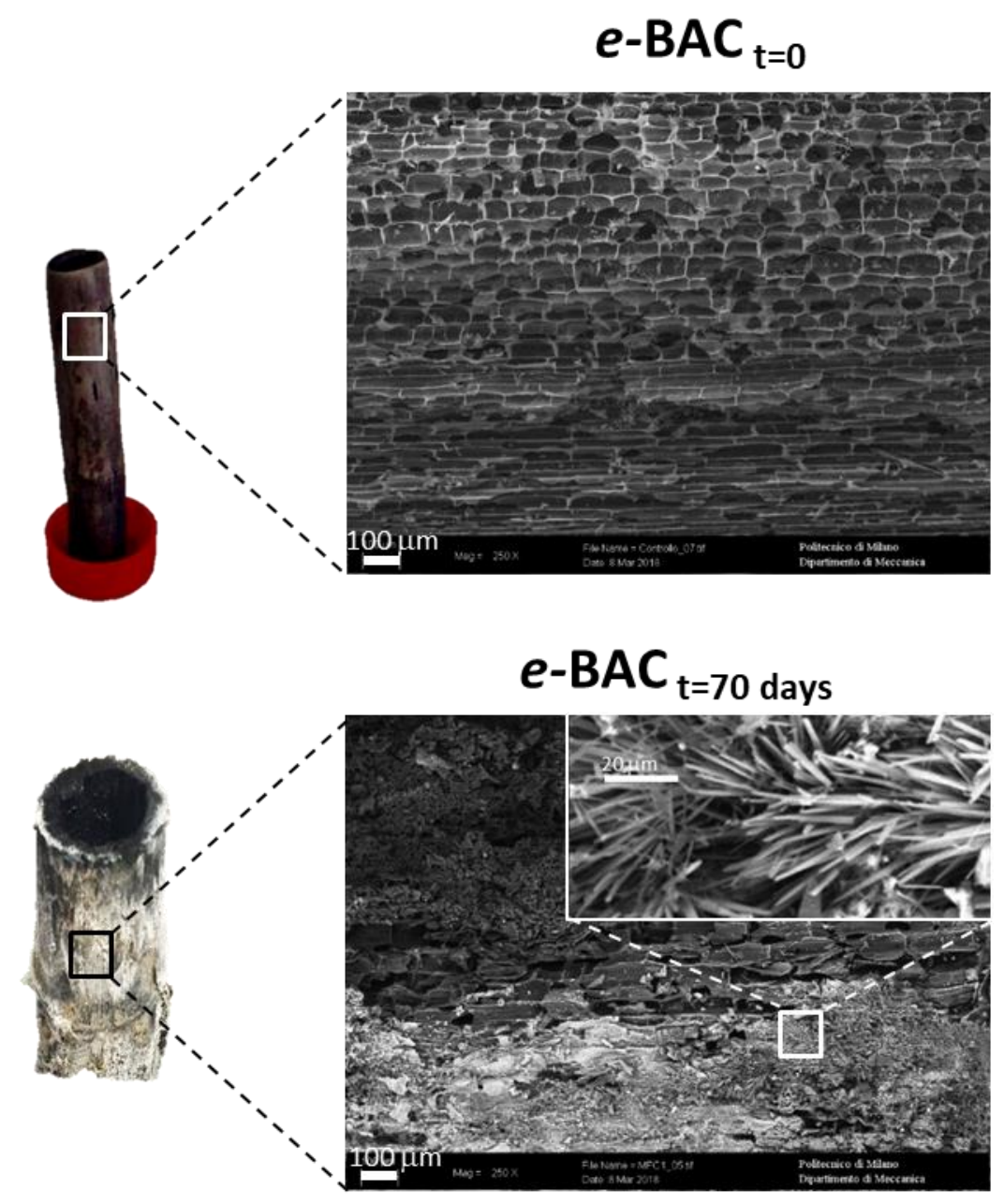

Fig.6 - Pictures and SEM images of the $e-\mathrm{BAC}$ at $\mathrm{t}=0$ and after 70 days operation in BES.

454 From ICP-MS, several elements originally contained in the synthetic wastewater were retrieved on the $e$ 455 BAC. Na content in the solid material increased by 79 folds, as compared its initial value. Ca and P 456 increased by 1.3 and 5 folds, respectively. Nitrogen was not measured in this work and would deserve 457 particular attentions in future experiments.

458 Salts deposition likely caused a decrease in the availability of the electroactive sites on the cathode and 459 clogged its porous texture. Accordingly, BET surface area measured at day 70 was under the instrumental 460 detection limit. Even if the precise value could not be measured, the $e$-BAC material underwent a decrease 461 of at least two-orders of magnitude in available surface area, along the 70-days test.

462 The phenomenon of salts deposition in air-exposed biocathodes was recently documented in the 463 literature by Santini et al. [14]. Together with carbonates, other salts are likely to deposit (such as struvite 464 and other salts containing macro-e micro-nutrients previously dissolved or suspended in the wastewater). 
This aspect could be of great interest for environmental application such as nutrients recovery in agrofood systems. When salts deposition clogs the cathode, impeding charge transfer processes, the e-biochar cathode could be substituted with a new one. The $e$-biochar enriched of plant nutrients might be recycled directly as agricultural soil conditioner. Biochar is widely considered as a soil-fertility promoter and a way to achieve long-term carbon storage [68]. Thereby, salts deposition phenomena on e-BACs can be considered as an advantage, to maximize nutrients recovery from wastewater in agro-food systems. On the other hand, future studies in this field should consider to detect possible contaminants (e.g. heavy metals, antibiotics, etc.) that might be contained in the treated wastewater.

\section{CONCLUSIONS}

$474 e$-biochar was prepared by controlled pyrolysis of Giant Cane stalks and characterized for physico475 chemical and electrochemical features. The structure and shape of Giant Cane were maintained after the 476 pyrolysis process and it was advantageous in building cylindrical and self-structured air-exposed 477 biocathode. This new material might reduce the need of technological materials in BES, and the cost of 478 bioelectrodes, especially for some applications. The fragility of the $e$-BAC structure represents an actual 479 drawback which needs an improvement, this might be overcome by addition of compounds that anyway must not decrease the conductivity and properties of the overall matrix. The step forward would be to work on the structure and prepare composite materials through which the thickness would result 482 increased, together with an enhanced rigidity. Despite improvements would be needed to achieve current/power densities of more technological and optimized materials, the e-biochar could open new 484 frontiers in BES' architectures, where energy harvesting is not the main goal. The produced currents 485 induced ions migration and salts deposition, clogging porous texture and enriching $e$-biochar of minerals. 486 This approach goes into the direction of achieving fully-recyclable BES architectures, directly reusable to 487 produce soil fertilizers. In parallel, further developments are needed to design bigger scale 488 biocathodes/anodes and to optimize their properties and performances, according to the desired 489 application.

\section{AKNOWLEDGEMENTS}

491 This work was financed by the SIR 2014 Grant (PROJECT RBSI14JKU3, BiofuelcellAPP), Italian Ministry of 492 University and Research (MIUR) and by the Research Fund for the Italian Electrical System in compliance 493 with the Decree of March 19th, 2009. Authors thank Prof. S. R. Pilu from the University of Milan who 494 furnished the Giant Cane stalks. 


\section{REFERENCES}

496 [1] Wei J, Liang P, Huang X. Recent progress in electrodes for microbial fuel cells. Bioresour Technol 2011;102:9335-44. doi:10.1016/j.biortech.2011.07.019.

[2] Zhou M, Chi M, Luo J, He H, Jin T. An overview of electrode materials in microbial fuel cells. J Power Sources 2011;196:4427-35. doi:10.1016/j.jpowsour.2011.01.012.

500

501

502

503

[3] Santoro C, Artyushkova K, Gajda I, Babanova S, Serov A, Atanassov P, et al. Cathode materials for ceramic based microbial fuel cells (MFCs). Int J Hydrogen Energy 2015;40:14706-15. doi:10.1016/j.ijhydene.2015.07.054.

[4] Kumar GG, Sarathi VGS, Nahm KS. Recent advances and challenges in the anode architecture and their modifications for the applications of microbial fuel cells. Biosens Bioelectron 2013;43:46175. doi:10.1016/j.bios.2012.12.048.

[5] You J, Santoro C, Greenman J, Melhuish C, Cristiani P, Li B, et al. Micro-porous layer (MPL)-based anode for microbial fuel cells. Int J Hydrogen Energy 2014;39:21811-8. doi:10.1016/j.ijhydene.2014.07.136.

[6] Santoro C, Lei Y, Li B, Cristiani P. Power generation from wastewater using single chamber microbial fuel cells (MFCs) with platinum-free cathodes and pre-colonized anodes. Biochem Eng J 2012;62:8-16. doi:10.1016/j.bej.2011.12.006.

[7] Santoro C, Agrios A, Pasaogullari U, Li B. Effects of gas diffusion layer (GDL) and micro porous layer (MPL) on cathode performance in microbial fuel cells (MFCs). Int J Hydrogen Energy 2011;36:13096-104. doi:10.1016/j.ijhydene.2011.07.030.

[8] Srikanth S, Pant D, Dominguez-Benetton X, Genné I, Vanbroekhoven K, Vermeiren P, et al. Gas Diffusion Electrodes Manufactured by Casting Evaluation as Air Cathodes for Microbial Fuel Cells (MFC). Materials (Basel) 2016;9:601. doi:10.3390/ma9070601.

[9] Terayama Y, Haji T, Furukawa S, Nomura M, Nishihara M, Lyth SM, et al. Carbon black / PTFE composite hydrophobic gas diffusion layers for a water-absorbing porous electrolyte electrolysis cell. Int J Hydrogen Energy 2018;43:2018-25. doi:10.1016/J.IJHYDENE.2017.12.045.

Rago L, Cristiani P, Villa F, Zecchin S, Colombo A, Cavalca L, et al. Influences of dissolved oxygen concentration on biocathodic microbial communities in microbial fuel cells. Bioelectrochemistry 
2017;116:39-51. doi:10.1016/j.bioelechem.2017.04.001.

524 [11] Guerrini E, Grattieri M, Faggianelli A, Cristiani P, Trasatti S. PTFE effect on the electrocatalysis of the oxygen reduction reaction in membraneless microbial fuel cells. Bioelectrochemistry 2015;106:240-7. doi:10.1016/j.bioelechem.2015.05.008.

[12] Fan Y, Han S-K, Liu H, Keller J, Buisman CJ, Rittmann BE, et al. Improved performance of CEA microbial fuel cells with increased reactor size. Energy Environ Sci 2012;5:8273. doi:10.1039/c2ee21964f.

[13] Katuri KP, Kalathil S, Ragab A, Bian B, Alqahtani MF, Pant D, et al. Dual-Function Electrocatalytic and Macroporous Hollow-Fiber Cathode for Converting Waste Streams to Valuable Resources Using Microbial Electrochemical Systems. Adv Mater 2018:1707072. doi:10.1002/adma.201707072.

[14] Santini M, Marzorati S, Fest-Santini S, Trasatti S, Cristiani P. Carbonate scale deactivating the biocathode in a microbial fuel cell. J Power Sources 2017;356. doi:10.1016/j.jpowsour.2017.02.088.

[15] Zhang F, Pant D, Logan BE. Long-term performance of activated carbon air cathodes with different diffusion layer porosities in microbial fuel cells. Biosens Bioelectron 2011;30:49-55. doi:10.1016/J.BIOS.2011.08.025.

540

[16] Pant D, Van Bogaert G, Porto-Carrero C, Diels L, Vanbroekhoven K. Anode and cathode materials characterization for a microbial fuel cell in half cell configuration. Water Sci Technol

[17] Rossi R, Yang W, Zikmund E, Pant D, Logan BE. In situ biofilm removal from air cathodes in 544

[18] Cheng S, Liu H, Logan BE. Increased performance of single-chamber microbial fuel cells using an

[19] Kim JR, Cheng S, Oh S-E, Logan BE. Power Generation Using Different Cation, Anion, and 
doi:10.1021/es062202m.

552 [20] Franks AE, Nevin KP. Microbial fuel cells, a current review. Energies 2010;3:899-919. doi:10.3390/en3050899.

554

555

556

[21] Rismani-Yazdi H, Carver SM, Christy AD, Tuovinen OH. Cathodic limitations in microbial fuel cells: An overview. J Power Sources 2008;180:683-94. doi:10.1016/j.jpowsour.2008.02.074.

[22] Ioannidou O, Zabaniotou A. Agricultural residues as precursors for activated carbon production-A review. Renew Sustain Energy Rev 2007;11:1966-2005. doi:10.1016/j.rser.2006.03.013.

[23] Yuan Y, Liu T, Fu P, Tang J, Zhou S. Conversion of sewage sludge into high-performance bifunctional electrode materials for microbial energy harvesting. J Mater Chem A 2015;3:847582. doi:10.1039/C5TA00458F.

[24] Qian K, Kumar A, Zhang H, Bellmer D, Huhnke R. Recent advances in utilization of biochar. Renew Sustain Energy Rev 2015;42:1055-64. doi:10.1016/j.rser.2014.10.074.

[25] Huggins T, Wang H, Kearns J, Jenkins P, Ren ZJ. Biochar as a sustainable electrode material for electricity production in microbial fuel cells. Bioresour Technol 2014;157:114-9. doi:10.1016/j.biortech.2014.01.058.

[26] Chen S, Tang J, Fu L, Yuan Y, Zhou S. Biochar improves sediment microbial fuel cell performance in low conductivity freshwater sediment n.d. doi:10.1007/s11368-016-1452-z.

[27] Cruz Viggi C, Simonetti S, Palma E, Pagliaccia P, Braguglia C, Fazi S, et al. Enhancing methane production from food waste fermentate using biochar: the added value of electrochemical testing in pre-selecting the most effective type of biochar. Biotechnol Biofuels 2017;10:303. doi:10.1186/s13068-017-0994-7.

[28] Chen S, Rotaru A-E, Shrestha PM, Malvankar NS, Liu F, Fan W, et al. Promoting interspecies electron transfer with biochar. Sci Rep 2014;4:5019. doi:10.1038/srep05019.

[29] Ma M, You S, Wang W, Liu G, Qi D, Chen X, et al. Biomass-Derived Porous Fe 3 C/Tungsten Carbide/Graphitic Carbon Nanocomposite for Efficient Electrocatalysis of Oxygen Reduction. ACS Appl Mater Interfaces 2016;8:32307-16. doi:10.1021/acsami.6b10804.

[30] Huggins TM, Pietron JJ, Wang H, Ren ZJ, Biffinger JC. Graphitic biochar as a cathode electrocatalyst support for microbial fuel cells. Bioresour Technol 2015;195:147-53. 
580

581

[31] Yuan H, Deng L, Qi Y, Kobayashi N, Tang J. Nonactivated and activated biochar derived from bananas as alternative cathode catalyst in microbial fuel cells. ScientificWorldJournal 2014;2014:832850. doi:10.1155/2014/832850.

[32] Chen Q, Pu W, Hou H, Hu J, Liu B, Li J, et al. Activated Microporous-Mesoporous Carbon Derived from Chestnut Shell as a Sustainable Anode Material for High Performance Microbial Fuel Cells. Elsevier Ltd; 2017. doi:10.1016/j.biortech.2017.09.086.

[33] Marzorati S, Schievano A, Colombo A, Lucchini G, Cristiani P. Ligno-cellulosic materials as airwater separators in low-tech microbial fuel cells for nutrients recovery. J Clean Prod 2018;170:1167-76. doi:10.1016/J.JCLEPRO.2017.09.142.

[34] Corno L, Pilu R, Adani F. Arundo donax L.: A non-food crop for bioenergy and bio-compound production. Biotechnol Adv 2014;32:1535-49. doi:10.1016/j.biotechadv.2014.10.006.

[35] Valli F, Trebbi D, Zegada-Lizarazu W, Monti A, Tuberosa R, Salvi S. In vitro physical mutagenesis of giant reed (Arundo donax L.). GCB Bioenergy 2017;9:1380-9. doi:10.1111/gcbb.12458.

[36] Basso MC, Cerrella EG, Buonomo EL, Bonelli PR, Cukierman AL. Thermochemical Conversion of Arundo Donax into Useful Solid Products. Energy Sources 2005;27:1429-38. doi:10.1080/009083190523280.

[37] Jeguirim M, Trouvé G. Pyrolysis characteristics and kinetics of Arundo donax using thermogravimetric analysis. Bioresour Technol 2009;100:4026-31. doi:10.1016/j.biortech.2009.03.033.

[38] Longhi M, Marzorati S, Checchia S, Sacchi B, Santo N, Zaffino C, et al. Sugar-based catalysts for oxygen reduction reaction. Effects of the functionalization of the nitrogen precursors on the electrocatalytic activity. Electrochim Acta 2016. doi:10.1016/j.electacta.2016.11.036.

[39] Santini M, Guilizzoni M, Fest-Santini S. X-ray computed microtomography for drop shape analysis and contact angle measurement. J Colloid Interface Sci 2013;409:204-10. doi:10.1016/J.JCIS.2013.06.036.

[40] Lukaszewski M, Soszko M, Czerwiński A. Electrochemical methods of real surface area determination of noble metal electrodes - an overview. Int J Electrochem Sci 2016;11:4442-69. 
doi:10.20964/2016.06.71.

608

609

610

611

612

613

614

615

616

617

618

619

620

621

622

623

624

625

626

627

628

629

630

631

632

633

634

[41] Du F, Yu D, Dai L, Ganguli S, Varshney V, Roy AK. Preparation of Tunable 3D Pillared Carbon Nanotube Graphene Networks for High Performance Capacitance. Chem Mater 2011:4810-6. doi:10.1021/cm2021214.

[42] Capacitance limits of high surface area activated carbons for double layer capacitors. Carbon N Y 2005;43:1303-10. doi:10.1016/J.CARBON.2005.01.001.

[43] Rago L, Guerrero J, Baeza JA, Guisasola A. 2-Bromoethanesulfonate degradation in bioelectrochemical systems. Bioelectrochemistry 2015;105:44-9. doi:10.1016/j.bioelechem.2015.05.001.

[44] Parameswaran P, Torres Cl, Lee HS, Krajmalnik-Brown R, Rittmann BE. Syntrophic interactions among anode respiring bacteria (ARB) and non-ARB in a biofilm anode: Electron balances. Biotechnol Bioeng 2009;103:513-23. doi:10.1002/bit.22267.

[45] Pasternak G, Greenman J, leropoulos I. Comprehensive Study on Ceramic Membranes for LowCost Microbial Fuel Cells. ChemSusChem 2015:88-96. doi:10.1002/cssc.201501320.

[46] Rago L, Zecchin S, Marzorati S, Goglio A, Cavalca L, Cristiani P, et al. A study of microbial communities on terracotta separator and on biocathode of air breathing microbial fuel cells. Bioelectrochemistry 2018;120:18-26. doi:10.1016/J.BIOELECHEM.2017.11.005.

[47] Ruggeberg M, Burgert I, Speck T. Structural and mechanical design of tissue interfaces in the giant reed Arundo donax. J R Soc Interface 2010;7:499-506. doi:10.1098/rsif.2009.0273.

[48] Ferrari AC, Robertson J. Interpretation of Raman spectra of disordered and amorphous carbon. Phys Rev B 2000;61:14095-107. doi:10.1103/PhysRevB.61.14095.

[49] Marzorati S, Vasconcelos JM, Ding J, Longhi M, Colavita PE, Carrette L, et al. Template-free ultraspray pyrolysis synthesis of N/Fe-doped carbon microspheres for oxygen reduction electrocatalysis. J Mater Chem A 2015;3:18920-7. doi:10.1039/C5TA02570B.

[50] Bernard S, Beyssac O, Benzerara K, Findling N, Tzvetkov G, Brown GE. XANES, Raman and XRD study of anthracene-based cokes and saccharose-based chars submitted to high-temperature pyrolysis. Carbon N Y 2010;48:2506-16. doi:10.1016/j.carbon.2010.03.024.

[51] Canado LG, Takai K, Enoki T, Endo M, Kim YA, Mizusaki H, et al. General equation for the 
determination of the crystallite size la of nanographite by Raman spectroscopy. Appl Phys Lett 2006;88:1998-2001. doi:10.1063/1.2196057.

[52] Deprez N, McLachlan DS. The analysis of the electrical conductivity of graphite conductivity of graphite powders during compaction. J Phys D Appl Phys 1988;21:101-7. doi:10.1088/0022$3727 / 21 / 1 / 015$.

[53] Pierson HO. Handbook of Carbon, Graphite, Diamond and Fullerenes. Handb Carbon, Graph Diam Fullerenes 1993:25-69. doi:http://dx.doi.org/10.1016/B978-0-8155-1339-1.50008-6.

[54] Barroso-Bogeat A, Alexandre-Franco M, Fernández-González C, Macías-García A, Gómez-Serrano V. Electrical conductivity of activated carbon-metal oxide nanocomposites under compression: a comparison study. Phys Chem Chem Phys 2014;16:25161-75. doi:10.1039/C4CP03952A.

[55] Adinaveen T, Vijaya JJ, Kennedy L. Comparative Study of Electrical Conductivity on Activated Carbons Prepared from Various Cellulose Materials. Arab J Sci Eng 2016;41:55-65. doi:10.1007/s13369-014-1516-6.

[56] 9.3.Double layer capacitance of carbon.pdf n.d.

[57] Liu Y, Liu H, Wang C, Hou S-X, Yang N. Sustainable Energy Recovery in Wastewater Treatment by Microbial Fuel Cells: Stable Power Generation with Nitrogen-doped Graphene Cathode. Environ Sci Technol 2013;47:13889-95. doi:10.1021/es4032216.

[58] Kodali M, Santoro C, Herrera S, Serov A, Atanassov P. Bimetallic platinum group metal-free catalysts for high power generating microbial fuel cells. J Power Sources 2017;366:18-26. doi:10.1016/j.jpowsour.2017.08.110.

[59] Cristiani P, Carvalho ML, Guerrini E, Daghio M, Santoro C, Li B. Cathodic and anodic biofilms in Single Chamber Microbial Fuel Cells. Bioelectrochemistry 2013;92:6-13. doi:10.1016/j.bioelechem.2013.01.005.

[60] Nguyen MT, Mecheri B, Iannaci A, D’Epifanio A, Licoccia S. Iron/Polyindole-based Electrocatalysts to Enhance Oxygen Reduction in Microbial Fuel Cells. Electrochim Acta 2016;190:388-95. doi:10.1016/j.electacta.2015.12.105.

[61] Cristiani P, Carvalho ML, Guerrini E, Daghio M, Santoro C, Li B. Cathodic and anodic biofilms in Single Chamber Microbial Fuel Cells. Bioelectrochemistry 2013;92:6-13. 
doi:10.1016/j.bioelechem.2013.01.005.

664

665

666

667

668

669

670

671

672

673

674

675

676

677

678

679

680

681

682

683

684

[62] Ruiz-Rosas R, Valero-Romero MJ, Salinas-Torres D, Rodríguez-Mirasol J, Cordero T, Morallón E, et al. Electrochemical Performance of Hierarchical Porous Carbon Materials Obtained from the Infiltration of Lignin into Zeolite Templates. ChemSusChem 2014;7:1458-67. doi:10.1002/cssc.201301408.

[63] Strelko V., Kuts V., Thrower P. On the mechanism of possible influence of heteroatoms of nitrogen, boron and phosphorus in a carbon matrix on the catalytic activity of carbons in electron transfer reactions. Carbon N Y 2000;38:1499-503. doi:10.1016/S0008-6223(00)00121-4.

[64] Gajda I, Stinchcombe A, Greenman J, Melhuish C, leropoulos I. Microbial fuel cell e A novel selfpowered wastewater electrolyser for electrocoagulation of heavy metals 2016. doi:10.1016/j.ijhydene.2016.06.161.

[65] Gajda I, Greenman J, Melhuish C, Santoro C, Li B, Cristiani P, et al. Water formation at the cathode and sodium recovery using Microbial Fuel Cells (MFCs). Sustain Energy Technol Assessments 2014;7:187-94. doi:10.1016/j.seta.2014.05.001.

[66] Santini M, Marzorati S, Fest-Santini S, Trasatti S, Cristiani P. Carbonate scale deactivating the biocathode in a microbial fuel cell. J Power Sources 2017;356:400-7. doi:10.1016/j.jpowsour.2017.02.088.

[67] Gajda I, Greenman J, Melhuish C, Santoro C, Li B, Cristiani P, et al. Electro-osmotic-based catholyte production by Microbial Fuel Cells for carbon capture. Water Res 2015. doi:10.1016/j.watres.2015.08.014.

[68] Woolf D, Amonette JE, Street-Perrott FA, Lehmann J, Joseph S. Sustainable biochar to mitigate global climate change. Nat Commun 2010;1:1-9. doi:10.1038/ncomms1053. 